\title{
EFFECT OF A FREE RADICAL SCAVENGER, EDARAVONE, ON FREE RADICAL REACTIONS \\ - RELATED SIGNAL TRANSDUCTION AND CEREBRAL VASOSPASM IN THE RABBIT SUBARACHNOID HEMORRHAGE MODEL -
}

\begin{abstract}
Akira Munakata, M.D.
Abstract OBJECTIVE: It is hypothesized that free radical reactions evoked by oxyhemoglobin (oxyHb) cause cerebral vasospasm after aneurysmal subarachnoid hemorrhage $(\mathrm{SAH})$, even though the detailed mechanisms have not yet been fully established. The aims of this study were thus to investigate, through the use of the doublehemorrhage rabbit model, the possibility that using a potent free radical scavenger, edaravone, will show amelioration of cerebral vasospasm, and to delineate the mechanism of signal transduction that causes cerebral vasospasm. METHODS: In the SAH group, SAH was simulated using the double-hemorrhage rabbit model. In the treatment group, edaravone $(0.6 \mathrm{mg} / \mathrm{kg})$ was injected into the central ear vein. Ninety-six hours after SAH, the basilar artery was excised. The degree of cerebral vasospasm was evaluated by measuring the diameter of each basilar artery, and the expression of Rho-kinase in the vascular wall was examined by Western blotting. RESULTS: The diameter of the basilar artery in the edaravone-treated group was $0.71 \pm 0.06 \mathrm{~mm}$, which was statistically significantly larger than that in the nontreated SAH group $(0.50 \pm 0.03 \mathrm{~mm} ; P<0.01)$. The expression of Rho-kinase in the edaravonetreated group was statistically significantly reduced in comparison to that of the nontreated SAH group $(P<0.01)$. CONCLUSION: Results from this study indicate that edaravone may potentially serve as an agent in the prevention of cerebral vasospasm in patients after SAH. In addition, it might be suggested that the free radical reaction mediated by oxyHb is concerned with the regulation of the Rho/Rho-kinase pathway.
\end{abstract}

Hirosaki Med. J. 61, Supplement : S197-S203, 2010

Key words: Cerebral vasospasm; edaravone; free radical scavenger; Rho-kinase; subarachnoid hemorrhage.

\section{Objective}

It is hypothesized that free radical reactions, such as lipid peroxide production in the arterial smooth muscle layer, evoked by oxyhemoglobin (oxyHb) released from a subarachnoid clot cause cerebral vasospasm after aneurysmal subarachnoid hemorrhage $(\mathrm{SAH})$. $^{9,15,22,23,27,49)}$ In fact, previous studies using free radical scavengers in experimental SAH models showed amelioration of cerebral vasospasm as a result of scavenging free radicals. ${ }^{3,11,25,53)}$

Edaravone (3-methyl-1-phenyl-2-pyrazolin5 -one), a potent free radical scavenger which is widely used in Japan to improve functional outcomes in patients suffering from acute ischemic stroke. ${ }^{43,52)}$ In addition, we found a trend toward a lower incidence of delayed ischemic neurological deficits (DINDs) and lower incidence of poor outcome caused by cerebral vasospasm in edaravone-treated patients with aneurysmal $\mathrm{SAH}^{33)}$

Several recent studies have revealed that intracellular signal transduction of vascular smooth muscle cells, especially the Rho/Rhokinase pathway ${ }^{8,18,38,39,49)}$, is activated during the development of cerebral vasospasm and, as a result, a sustained contraction of arterial smooth muscle cells occurs. ${ }^{1838,49)}$ Even though it has been speculated that free radical reactions, evoked by oxyHb released from a subarachnoid clot, induce sustained contraction through an
Department of Neurosurgery, Hirosaki University Graduate School of Medicine, 5 Zaifu-cho, Hirosaki, 036-8562, Japan
Fax: +81-172-39-5116

E-mail:munax@cc.hirosaki-u.ac.jp 
activated intracellular signal transduction, detailed mechanisms of this free radical reactioninduced sustained contraction have not yet been clarified. $^{49)}$

The aims of this study were to investigate, through the use of the double -hemorrhage rabbit model, the possibility that using edaravone in experimental SAH models will show amelioration of cerebral vasospasm and to delineate the mechanism of signal transduction that causes sustained contraction in cerebral vasospasm.

\section{Materials and Methods}

All experimental protocols were approved by the Hirosaki University Animal Research Committee. Thirty Japanese white rabbits weighing 2.5 to $3.0 \mathrm{~kg}$ were used. All animals were randomly assigned to three groups: group 1 (sham, $\mathrm{n}=10$ ), the animals were given an intravenous injection of edaravone with sham surgery; group $2(\mathrm{SAH}, \mathrm{n}=10)$, SAH was produced; and group 3 (SAH-edaravone, $\mathrm{n}=10$ ), $\mathrm{SAH}$ was produced and the animals were given an intravenous injection of edaravone.

\section{Production of SAH}

In groups 2 and 3, SAH was produced according to the double-hemorrhage method. ${ }^{4,31,45)}$ The animals were anesthetized with an intravenous injection of pentobarbital $(30 \mathrm{mg}$ / $\mathrm{kg}$ ) and an intramuscular injection of ketamine $(20 \mathrm{mg} / \mathrm{kg})$.

After anesthesia, under spontaneous breathing, a 23-gauge butterfly needle was percutaneously placed in the cisterna magna, and cerebrospinal fluid (1.0 to $1.5 \mathrm{~mL}$ ) was aspirated under aseptic technique. Animals in group 1 (Sham) were injected $1.5 \mathrm{~mL}$ of saline solution. In groups 2 and 3 (SAH and SAH-edaravone), nonheparinized arterial blood from the femoral artery, $1.5 \mathrm{ml}$, was injected into the cisterna magna over one to two minutes. Animals were then placed in a $30^{\circ}$ head-down, tilted position for 15 minutes to ensure that blood spread into the basal cistern.
Forty-eight hours afterwards the second SAH and sham surgery were performed in the same manner as the first.

\section{Intravenous injection of edaravone}

In groups 1 and 3 , edaravone $(0.6 \mathrm{mg} / \mathrm{kg})$ was injected into the central ear vein over 1 to 2 minutes, twice a day for 96 hours after SAH.

\section{Histological Evaluation}

Perfusion-fixation was performed at ninetysix hours after SAH. Five animals of each group were deeply anesthetized using $100 \mathrm{mg}$ / $\mathrm{kg}$ pentobarbital, the thorax was opened, and a cannula was immediately inserted into the ascending aorta via the left ventricle. Perfusion fixation was performed at $75 \mathrm{~mm} \mathrm{Hg}$ with 400 $\mathrm{mL}$ heparinized physiological saline $(5000 \mathrm{U}$ / $500 \mathrm{~mL}$ ), followed by $500 \mathrm{~mL}$ of phosphatebuffered 4\% paraformaldehyde ( $\mathrm{pH} 7.4$ ). Finally, the brain was carefully removed so as not to stretch and injure the basilar artery.

The tissue was dehydrated in graded alcohol and embedded in paraffin. All 6 - $\mu$ m-thick sections were cut vertically, mounted on a glass slide, and stained with hematoxylin-eosin (HE) or with periodic acid-Schiff stain (PAS).

Cerebral vasospasm was evaluated using the HE-stained sections. Vessel patency was quantified by measuring the basilar artery circumference with the National Institutes of Health image program (version 1.62). To correct for vessel deformation and off-transverse sections, the internal circumferences of five different sections of each vessel, separated by $200 \mu \mathrm{m}$, were measured and averaged. The luminal crosssectional area of each vessel was estimated with the use of the calculated radius ( $r$ ) value obtained from the measured circumference $(r$ $=$ measured circumference $/ 2 \pi$; area of circle $=$ $\pi r^{2}$ ). The mean diameter of the basilar arteries was calculated from the calculated radius (diameter $=2 \mathrm{r}$ ).

Lipid peroxide production was evaluated using the PAS-stained sections ${ }^{34)}$. Expressions of lipid 
peroxide production in vascular smooth muscle were reviewed by two blinded, independent observers ( $\mathrm{TN}$ and $\mathrm{MN}$ ). The intensity in the vascular smooth muscle layer was graded on a 3 -point scale, from 0 (least intense) to 2 (most intense). Differences in the score graded were resolved by discussion with a third observer (HO).

\section{Western blotting}

Another five animals of each group were killed by the intravenous injection of high dose pentobarbital $(300 \mathrm{mg} / \mathrm{kg})$ on day four after SAH. The basilar arteries were immediately removed and stored at $-80^{\circ} \mathrm{C}$ until analysis.

Western blotting followed the standard technique. Primary antibody included goat antiRock II (sc1851; Santa Cruz Biotechnology; Santa Cruz, CA). The membrane was incubated with the appropriate Cruz Marker compatible secondary antibody. Bands were detected with a chemiluminescence detection kit (ECL plus; Amersham Bioscience). Blot bands were quantified using the densitometry method (Scion image Beta 4.02), $n=5$ for each group. The value of the sham is expressed as $100 \%$, and other groups are expressed as a percentage of the sham group.

\section{Statistical analysis}

Data are expressed as mean \pm SEM. Differences between individual groups were analyzed using post hoc t-tests supported by $\mathrm{JMP}^{\circledR}$ (Version 5; SAS Institute Inc., Cary, NC, USA). $P<0.05$ was considered statistically significant.

\section{Results}

\section{Evaluation of cerebral vasospasm}

In group $2(\mathrm{SAH}, \mathrm{n}=5)$, mean $\pm \mathrm{SEM}$ basilar artery diameter was statistically significantly reduced four days after $\mathrm{SAH}$ versus group 1 (Sham, $\mathrm{n}=5) \quad(0.50 \pm 0.03 \mathrm{~mm}$ versus $0.73 \pm$ $0.05 \mathrm{~mm}, P<0.01$ ). After SAH, mean $\pm \mathrm{SEM}$ basilar artery diameter was greater in group 3 $(\mathrm{SAH}+$ edaravone, $\mathrm{n}=5)$ versus group $2(0.71$ $\pm 0.06 \mathrm{~mm}$ versus $050 \pm 0.03 \mathrm{~mm}, P<0.01$ ). In addition, marked corrugation of the internal elastic lamina around the wall, with thickening of the vascular smooth muscle layer, was seen in group 2. In contrast, the corrugation was much less remarkable in group 3.

\section{Lipid peroxide production in the vascular smooth muscle layer}

In group 1 (Sham, $\mathrm{n}=5$ ), lipid peroxide production in the vascular smooth muscle layer was evaluated as a score of 0.2. In group 2 (SAH, $\mathrm{n}=5$ ), lipid peroxide production was detected diffusely at the vascular smooth muscle layer, and the average score was 2.0. In contrast, all sections of group 3 ( $\mathrm{SAH}+$ edaravone, $\mathrm{n}=5$ ) showed lower lipid peroxide production, with an average score of 0.4 . With the Chi Squared test, a statistically significant difference in lipid peroxide production scores was found between groups 2 and $3(P<0.01)$.

\section{Expression of Rho-kinase}

In group $2(\mathrm{SAH}, \mathrm{n}=5)$, expression of Rho-kinase was significantly increased in the vascular smooth muscle cells by Western blotting $(P<0.01$; versus groups 1 and 3$)$.

\section{Discussion}

The transformation of oxyHb, released from a subarachnoid clot, into methemoglobin generates activated species of oxygen such as the superoxide anion, hydrogen peroxide and singlet oxygen ${ }^{10,17,32,50)}$. Oxygen radicals can initiate peroxidative reactions in membrane polyunsaturated fatty acid, producing lipid peroxides. And it has been speculated that lipid peroxide production in vascular smooth muscle layer causes cerebral vasospasm after SAH. It has thus been considered that scavenging free radicals in the subarachnoid space will ameliorate cerebral vasospasm. In fact, previous studies using free radical scavengers in experimental SAH models showed statistically significant amelioration of cerebral vasospasm, even though detailed mech- 
anisms as to how free radicals induce sustained contraction of vasucular smooth muscle have not yet been clarified. This study also revealed that using edaravone in an experimental rabbit $\mathrm{SAH}$ model also statistically significantly ameliorated lipid peroxide production in the vascular smooth muscle layer and cerebral vasospasm.

Several recent studies have revealed that the Rho/Rho-kinase pathway plays an important role in vascular diseases. And Sato et al. showed that the Rho/Rho-kinase pathway is activated during the development of cerebral vasospasm after SAH. It has been considered that the Rho/Rho-kinase pathway is activated by some trimeric G-protein-coupled receptors, including lysophosphatidic acid, thrombin, and serotonin receptors, which are linked to the Rho/Rhokinase pathway. The $\alpha$ subunits of $G_{i}, G_{q}, G_{12}$ and $\mathrm{G}_{13}$ activate Rho by regulating GDP/GTP exchange factors for Rho. Rho-kinase, which is activated by Rho, phosphorylates the myosinbinding subunit (MBS) of myosin phosphatase and, as a result, activity of myosin phosphatase is decreased. In addition, the activated Rho-kinase phosphorylates myosin light chain (MLC) at the Ser19 residue, which is the site phosphorylated by $\mathrm{Ca}^{2+} /$ calmodulin-dependent MLC kinase. Thus a sustained contraction of vascular smooth muscle was induced by Rho-kinase. But, the mechanism as to how SAH activates the Rho/ Rho-kinase pathway has not yet been clarified.

Wickman et al. have shown that the oxyHbmediated sustained contraction of vascular smooth muscle is dependent on the Rho/Rhokinase pathway and PKC, by using the selective inhibitors of Rho-kinase, Y-27632, and HA-1077, even though the mechanism by which oxyHb activates the Rho/Rho-kinase pathway has not yet been clarified. OxyHb has been shown to exhibit a number of signaling processes such as free radical reactions, elevation of intracellular $\mathrm{Ca}^{2+}$, activation of tyrosine kinases and mitogenactivated protein kinases. Whether free radical reactions or other reactions mediated by oxyHb play a role in the activation of the Rho/Rhokinase pathway has not yet been clarified. Since the Rho-kinase expression on Western blotting was statistically significantly reduced due to the amelioration of lipid peroxide production in the vascular smooth muscle layer by using edaravone, a potent free radical scavenger in the experimental rabbit SAH model, it could be speculated that the free radical reaction mediated by $о x y H b$ is concerned with the regulation of the Rho/Rho-kinase pathway.

In conclusion, results from this study indicate that edaravone (3-methyl-1-phenyl-2pyrazolin-5-one), a potent free radical scavenger, may serve as an agent in the prevention of cerebral vasospasm in patients after SAH, since intravenous administration of edaravone after the onset of SAH statistically significantly ameliorated lipid peroxide production in the vascular smooth muscle layer and basilar artery vasospasm after experimental $\mathrm{SAH}$ in rabbits. In addition, results from this study also indicate, for the first time, that free radical reactions mediated by oxyHb might play an important role in the Rho/Rho-kinase pathway by expressing Rho-kinase.

\section{References}

1) Amano M, Ito M, Kimura K, Fukata Y, Chihara K, Nakano T, Matsuura Y, Kaibuchi K: Phosphorylation and activation of myosin by Rho associated kinase (Rho-kinase). J Biol Chem 1996; 271:2024620249.

2) Arai T, Takeyama N, Tanaka T: Glutathione monoethyl ester and inhibition of the oxyhemoglobininduced increase in cytosolic calcium in cultured smooth muscle cells. J Neurosurg 1999;90:527-532.

3) Asano T, Sasaki T, Koide T, Takakura K, Sano K: Experimental evaluation of the beneficial effect of an antioxidant on cerebral vasospasm. Neurol Res 1984;6:49-53.

4) Baker KF, Zervas NT, Pile-Spellman J, Vacanti 
FX, Miller D: Angiographic evidence of basilar artery constriction in the rabbit: a new model of vasospasm. Surg Neurol 1987;27:107-112.

5) Barber AA, Bernheim F: Lipid peroxidation: its measurement, occurrence, and significance in animal tissues. Adv Geront Res 1976;2:355-403.

6) Betuing S, Daviaud D, Pages C, Bonnard E, Valet P, Lafontan M, Saulnier-Blache JS: G $\beta \gamma$ independent coupling of $\alpha_{2}$-adrenergic receptor to $\mathrm{p} 21^{\text {rhoA }}$ in preadipocytes. J Biol Chem 1998;273: 28700-28707.

7) Carrell RW, Winterbourn CC, Rachmilewitz EA: Activated oxgen and haemolysis. J Lipid Res 1977; 18:635-644.

8) Chrissobolis S, Sobey CG: Recent evidence for an involvement of rho-kinase in cerebral vascular disease. Stroke 2006;37:2174-2180.

9) Echlin F: Experimental vasospasm, acute and chronic, due to blood in the subarachnoid space. J Neurosurg 1971;35:646-656.

10) Gutteridge JMC: Iron promoters of the Fenton reaction and lipid peroxidation can be released from haemoglobin by peroxides. FEBS Lett 1986; 201:291-295.

11) Handa Y, Kaneko M, Takeuchi H, Tsuchida A, Kobayashi H, Kubota T: Effect of an antioxidant, ebselen, on development of chronic cerebral vasospasm after subarachnoid hemorrhage in primates. Surg Neurol 2000;53:323-329.

12) Hart MJ, Jiang X, Kozasa T, Roscoe W, Singer WD, Gilman AG, Sternweis PC, Bollag G: Direct stimulation of the guanine nucleotide exchange activity of p115 RhoGEF by $\mathrm{G}_{\alpha 13}$. Scinece 1998; 280:2112-2114.

13) Higashi M, Shimokawa H, Hattori T, Hiroki J, Mukai Y, Morikawa K, Ichiki T, Takahashi S, Takeshita A: Long-term inhibition of Rho-kinase suppresses angiotensin II-induced cardiovascular hypertrophy in rats in vivo: effect on endothelial NAD (P)H oxidase system. Circ Res 2003;93:767775 .

14) Ishizaki T, Maekawa M, Fujisawa K, Okawa K, Iwamatsu A, Fujita A, Watanabe N, Saito Y, Kakizuka A, Morii N: The small GTP-binding protein Rho binds to and activates a $160 \mathrm{kDa}$ Ser/Thr protein kinase homologous to myotonic dystrophy kinase. EMBO J 1996;15:1885-1893.

15) Kassell NF, Sasaki T, Colohan AR, Nazar G: Cerebral vasospasm following aneurysmal subarachnoid hemorrhage. Stroke 1985;16:562-572.

16) Katoh H, Aoki J, Yamaguchi Y, Kitano Y, Ichikawa A, Negishi M: Constitutively active $G_{\alpha 12}, G_{\alpha 13}$ and $\mathrm{G}_{\alpha q}$ induce Rho-dependent neurite retraction through different signaling pathways. J Biol Chem 1998;273:28700-28707.

17) Kellogg EW III, Fridovich I : Liposome oxidation and erythrocyte lysis by enzymatically generated superoxide and hydrogen peroxide. J Biol Chem 1977;252:6721-6728.

18) Kimura K, Ito M, Amano M, Chihara K, Fukata Y, Nakafuku M, Yamamori B, Feng J, Nakano T, Okawa K, Iwamatsu A, Kaibuchi K: Regulation of myosin phosphatase by Rho and Rho-associated kinase (Rho-kinase). Science 1996;12:245-248.

19) Kozasa T, Jiang X, Hart MJ, Stermweis PM, Singer WD, Gilman AG, Bollag G, Sternweis PC: p115 RhoGEF, a GTPase activating protein for $\mathrm{G}_{\alpha 12}$ and $\mathrm{G}_{\alpha 13}$. Scinece 1998;280:2109-2111.

20) Laher I, Zhang JH: Protein kinase C and cerebral vasospasm. J Cereb Blood Flow Metab 2001;21: 887-906.

21)Leung T, Manser E, Tan L, Lim L: A novel serine threonine kinase binding the Ras-related RhoA GTPase which translocate the kinase to peripheral membranes. J Biol Chem 1995;270: 29051-29054.

22) Macdonald RL, Weir BK: A review of hemoglobin and the pathogenesis of cerebral vasospasm. Stroke 1991;22:971-982.

23) Macdonald RL, Weir BK: Cerebral vasospasm and free radicals. Free Radic Biol Med 1994;16:633-643.

24) Macdonald RL, Weir BK, Young JD, GRACE MG: Cytoskeletal and extracellular matrix proteins in cerebral arteries following subarachnoid hemorrhage in monkeys. J Neurosurg 1992;76:81-90.

25) Matsui T, Asano T: Effects of new 21-aminosteroid tirilazad mesylate (U74006F) on chronic cerebral vasospasm in a "two-hemorrhage" model of beagle 
dogs. Neurosurgery 1994;34:1035-1039.

26) Matsui T, Amano M, Yamamoto T, Chihara K, Nakafuku M, Ito M, Nakano T, Okawa K, Iwamatsu A, Kaibuchi K: Rho-associated kinase, a novel serine/threonine kinase, as a putative target for the small GTP binding protein Rho. EMBO J 1996;15: 2208-2216.

27) Matsui T, Kaizu H, Itoh S, Asano T: The role of active smooth-muscle contraction in the occurrence of chronic vasospasm in the canine two-hemorrhage model. J Neurosurg 1994;80:276- 282.

28) Matsui T, Sugawa M, Johshita H, Takuwa Y, Asano $\mathrm{T}$ : Activation of the protein kinase C-mediated contractile system in canine basilar artery undergoing chronic vasospasm. Stroke 1991;22:1183-1187.

29) Matsui T, Takuwa Y, Johshita H, Yamashita $\mathrm{K}$, Asano T: Possible role of protein kinase C-dependent smooth muscle contraction in the pathogenesis of chronic cerebral vasospasm. J Cereb Blood Flow Metab 1991;11:143-149.

30) Matthew JM, Gustavo P, FedericoGL, Quoc-Anh T, Pablo FR, Rafael JT, Richard EC: Systemic administration of simvastatin after the onset of experimental subarachnoid hemorrhage attenuates cerebral vasospasm. Neurosurgery 2006;58:945-951.

31) Megyesi JF, Vollrath B, Cook DA, Findlay JM: In vivo animal models of cerebral vasospasm: a review. Neurosurgery 2000;46:448-460.

32) Misra HP, Fridovich I: The generation of superoxide radical during the autoxidation of hemoglobin. J Biol Chem 1972;247:6960-6962.

33) Munakata A, Ohkuma H, Nakano T, Shimamura N, Asano K, Naraoka M: Effect of a free radical scavenger, edaravone, in the treatment of patients with aneurysmal subarachnoid hemorrhage. Neurosurgery 2009;64:423-429.

34) Nakajima T, Sasakuri Y, Yamashita M, Yamashita S: Morphological study on lipid peroxides in the atheromatous plaque in human. Kasankashishitu Kenkyu 1991;5:13-17.

35) Sako M, Nishihara J, Ohta S, Wang J, Sakaki S: Role of protein kinase $\mathrm{C}$ in the pathogenesis of cerebral vasospasm after subarachnoid hemorrhage. J Cereb Blood Flow Metab 1993;13:247-254.
36) Sasaki S, Kuwabara H, Ohta S: Biological defence mechanism in the pathogenesis of prolonged cerebral vasospasm in the patients with ruptured intracranial aneurysms. Stroke 1986;17:196-202.

37) Sasaki S, Ohta S, Nakamura H: Free radical reaction and biological defence mechanism in the pathogenesis of prolonged vasospasm in experimental subarachnoid hemorrhage. J Cereb Blood Flow Metab 1988;8:1-8.

38) Sato M, Tani E, Fujikawa H, Kaibuchi K: Involvement of Rho-kinase-mediated phosphorylation of myosin light chain in enhancement of cerebral vasospasm. Circ Res 2000;87:195-200.

39) Scherer EQ, Herzog M, Wangemann P: Endothelin1-induced vasospasms of spiral modiolar artery are mediated by rho-kinase- induced $\mathrm{Ca}(2+)$ sensitization of contractile apparatus and reversed by calcitonin gene-related Peptide. Stroke 2002;33:2965-2971.

40) Seasholtz TM, Majumdar M, Brown JH: Rho as a mediation of $\mathrm{G}$ protein-coupled receptor signaling. Mol Pharmacol 1999;55:949-956.

41) Steele JA, Stockbridge N, Maljkovic G: Free radicals mediate actions of oxyhemoglobin on cerebrovascular smooth muscle cells. Circ Res 1991;68:416-423.

42) Takuwa Y, Matsui T, Abe Y, Nagafuji T, Yamashita $\mathrm{K}$, Asano T: Alterations in protein kinase $\mathrm{C}$ activity and membrane lipid metabolism in cerebral vasospasm after subarachnoid hemorrhage. J Cereb Blood Flow Metab 1993;13:409-415.

43) The Edaravone Acute Brain Infarction Study Group: Effect of a novel free radical scavenger, edaravone (MCI-186), on acute brain infarction: randomized, placebo-controlled, double-blind study at multicenters. Cerebrovasc Dis 2003;15:222-229.

44) Toshima Y, Satoh S, Ikegaki I, Asano T: A new model of cerebral microthrombosis in rats and the neuroprotective effect of a Rho-kinase inhibitor. Stroke 2000;31:2245-2250.

45) Tsurutani H, Ohkuma H, Suzuki S: Effects of thrombin inhibitor on thrombin-related signal transduction and cerebral vasospasm in the rabbit subarachnoid hemorrhage model. Stroke 2003;34:1497-1500. 
46) Uehata M, Ishizaki T, Satoh H, Ono T, Kawahara T, Morishita T, Tamakawa H, Yamagami K, Inui J, Maekawa M, Narumiya S: Calcium sensitization of smooth muscle mediated by a Rho-associated protein kinase in hypertension. Nature 1997;30:990994.

47) Vollmer DG, Hongo K, Ogawa H: A study of the effectiveness of the iron-chelating agent deferoxamine as vasospasm prophylaxis in a rabbit model of subarachnoid hemorrhage. Neurosurgery 1991;28:27-32.

48) Vollrath B, Cook D, Megyesi J, Findlay JM, Ohkuma $\mathrm{H}$ : Novel mechanism by which hemoglobin induces constriction of cerebral arteries. Eur J Pharmacol 1998;361:311-319.

49) Wickman G, Lan C, Vollrath B: Functional roles of the rho/rho kinase pathway and protein kinase $\mathrm{C}$ in the regulation of cerebrovascular constriction mediated by hemoglobin: relevance to subarachnoid hemorrhage and vasospasm. Circ Res 2003;92:809-816.

50) Winterbourn CC, McGrath BM, Carrell RW: Reactions involving superoxide and normal and unstable haemoglobins. Biochem J 1976;155:493502.

51) Zhang JH: Role of protein kinase $\mathrm{C}$ in cerebral vasospasm: past and future. Neurol Res 2000;22: 369-378.

52) Zhang N, Komine-Kobayashi M, Tanaka R, Liu M, Mizuno Y, Urabe T: Edaravone reduces early accumulation of oxidative products and sequential inflammatory responses after transient focal ischemia in mice brain. Stroke 2005;36:2220-2225.

53) Zuccarello M, Marsch JT, Schmitt G, Woodward J, Anderson DK: Effect of the 21-aminosteroid U-74006F on cerebral vasospasm following subarachnoid hemorrhage. J Neurosurg 1989;71:98-104. 